\title{
Effect of Cryogenic Treatment on Mechanical Properties of AISI 4340 and AISI 4140 Steel
}

\author{
ABDUL RAUF JAMALI*, WASEEM KHAN*, ALI DAD CHANDIO*, ZUBIA ANWER*, AND \\ MUHAMMAD HAYAT JOKHIO**
}

RECEIVED ON 18.01.2017 ACCEPTED ON 30.10.2018

\begin{abstract}
From last epoch till to date, AISI 4340 and AISI 4140 have been widely used in different engineering applications. These applications include bolt, screws, gears, drive shafts, crane shaft and piston rods for engines due to its upright mechanical properties, cost-effective and easily available in market. In present work, deep cryogenic treatment effect on the mechanical properties of AISI 4340 and AISI 4140 have been studied. Present work was carried out at laboratory scale and can be extended for mass production. Our work is simple, straight forward safe and economical. In our work, samples were heat treated in simple muffle furnace and followed by cryogenic treatment in liquid nitrogen. Before cryogenic treatment, all samples were normalized at $860^{\circ} \mathrm{C}$ to obtain homogenized microstructure. Samples were also compared conventionally heat treatment with quenched in oil quenchant. Experimental results showed that after cryogenic treatment with tempering treatment, one could easily increase the tensile strength, impact toughness and hardness. Advanced optical microscopy (IMM 901) and SEM (Scanning Electron Microscopy), FIT Quanta 200 methods have also been deployed to reveal and interpret the internal structure of samples. It was found from microstructure that cryogenic treated sample increases the impact strength, hardness and tensile strength as compared conventional heat treated quenching approaches.
\end{abstract}

Key Words: Cryogenic Treatment, Conventional Heat Treatment, Mechanical Properties, AISI 4340 Steel, AISI 4140 Steel.

\section{INTRODUCTION}

$\mathrm{F}$ Irom 1930-1940s, to improve the performance of cutting tool steels, cryoprocessing was used as the method of conventional heat transfer [1]. Cryogenic treatment is now used to increase the mechanical properties like wear resistance, hardness, tensile strength, impact toughness, reduction in residual stresses of materials. The low temperature heat treatment methods are two types: in "cold treatment" the temperature used about $-80^{\circ} \mathrm{C}$, where as in other method "cryogenic treatment" the temperature used is about $196^{\circ} \mathrm{C}$ and quenching media used as liquid nitrogen. Baldissera [2] has reported that after deep cryogenic treatment on tool and die steel grades, the toughness values are improved for these steel grades. The

Authors E-Mail: engr_raufjamali@yahoo.com, waseemkhan@neduet.edu.pk, alidad@neduet.edu.pk, zubia@neduet.edu.pk, mhayatj@yahoo.com) * Department of Metallurgical Engineering, NED University of Engineering \& Technology, Karachi, Pakistan.

** Department of Metallurgy \& Material Engineering, Dawood University of Engineering \& Technology, Karachi, Pakistan.

This is an open access article published by Mehran University Research Journal of Engineering and Technology, Jamshoro under the CC by 4.0 International License. 
precipitation of fine $\eta$ (eta) carbides has been reported after deep cryogenic treatment in AISI M2 [3], T1 [4] and AISI H13 [5]. In a previous work on AISI 4340, a decrease in toughness after deep cryogenic treatment has been investigated due to an increase in the martensite phase fraction [6].According to researchers a decrease in the retained austenite volume fraction with increasing soaking time in deep cryogenic treatment has also been observed [7-8].

The researchers accepted that the decrease in volume fraction of retained austenite gives improved effect on mechanical properties after deep cryogenic treatment of steels [9]. The main reason for the lower mechanical properties of high-speed steel subjected to the cold treatment is the smaller quantity of secondary martensite when retained austenite is transformed in the process of standard tempering [10].

Zablotskii et. at. [11] studied the macrostructure of several steel and found that most of the retained austenite in steels was transformed to martensite during cooling to $80^{\circ} \mathrm{C}$ and a small portion during cooling to $-196^{\circ} \mathrm{C}$. It was believed that transient carbide called $\eta$-carbide precipitated from the decomposition of martensite during tempering after deep cryogenic treatment. These fine carbide particles enhance the strength and toughness of the martensite matrix and also improve wear resistance [12-3]. Another claim is based on the strengthening of the material brought about by precipitation of fine carbides because of the cryogenic treatment [14].

In this experimental work, the mechanical properties i.e. hardness, tensile strength and impact toughness of medium carbon alloy steel after deep cryogenic treatment are studied [15]. The steel grades AISI 4340 and AISI 4140 are used due to their structural applications. At low temperature processing an increase in carbide formation increases the hardness of medium carbon low alloy steel.
Carbides are normally very hard and brittle due to their brittleness it should be dispersed in the soft matrix. The fine precipitation of $\eta$ carbides in martensitic matrix leads to an increase in hardness, impact toughness and tensile strength of medium carbon low alloy steel (i.e. AISI 4340 and AISI 4140) [16]. The cryogenic treatment in liquid nitrogen is also responsible for phase transformation from retained austenite to primary martensite which not possible in conventional quenching (i.e. austenite and oil quenched) [17].

\section{EXPERIMENTAL WORK}

The AISI 4340 and AISI 4140 were normalized in the heat treatment furnace (PLF 120/10). The material with round bar of $25 \mathrm{~mm}$ diameter was used for make samples for tensile testing and hardness test whereas the square material with $(10 \times 10 \mathrm{~mm})$ cross-section was used for making charpy impact specimens. The chemical composition of specimens was carried out by spark emission spectroscopy (SPECTRAPLUS 2110) as shown in Tables 1-2. The ASTM E8 was adopted for tensile testing (DTU-900H CB), ASTM E18-15 was used for hardness testing (500RA) whereas ASTM E23 used for impact testing (452 G-3). At first, the conventional quenching treatment is done in order to compare the results after cryogenic treatment.

All specimens were normalized at $860^{\circ} \mathrm{C}$ to obtain homogenized microstructure. All specimens were then conventionally quenched in oil quenchant. The hardening temperatures for AISI 4340 and AISI 4140 steel were used as 830 and $850^{\circ} \mathrm{C}$ respectively. Two specimens each of AISI 4340 and AISI 4140 steel were then tempered at 200 and $300^{\circ} \mathrm{C}$ while remaining specimens were cryogenically treated by soaking the specimens in liquid nitrogen for 24 hours. After cryogenic treatment, two specimens each of AISI 4340 and AISI 4140 steel were then tempered at 200 and $300^{\circ} \mathrm{C}$. The cryogenic treatment was done after the conventional quenching treatment on AISI 4340 and AISI 4140, as shown in Figs. 1-2 respectively. 
The sequence of heat treatment for AISI 4140 steel and AISI 4340 steel are shown in Tables 3-4 respectively.

After performing heat treatment sequence, the mechanical testing (i.e. Hardness testing, Tensile testing and impact testing) was done. The microstructure of normalized, conventional quenched, cryogenic treated and tempered specimens were then analyzed by using optical microscopy (IMM 901) and SEM, FIT Quanta 200. The samples for microstructural analysis were grind with grid sizes $80,120,180,240,320,400,600,800$ and 1000 respectively, then polished with colloidal alumina and etched with $2 \%$ Nital. The fractured surfaces obtained after tensile testing of both alloy steel grades were analyzed by using scanning electron microscopy.

\section{RESULTS AND DISCUSSION}

\subsection{Hardness}

The hardness testing was done with the help of Rockwell hardness testing machine using scale $\mathrm{C}$ (HRC). The hardness has done for various heat treated samples i.e. conventional oil quenched, tempered and cryogenic treated Specimens.

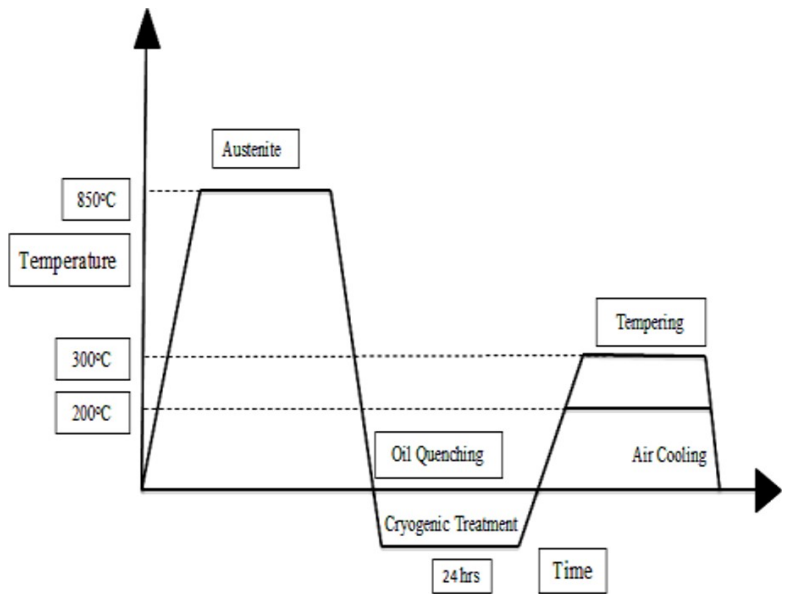

FIG. 1. AISI 4140 HEAT TREATMENT CYCLE

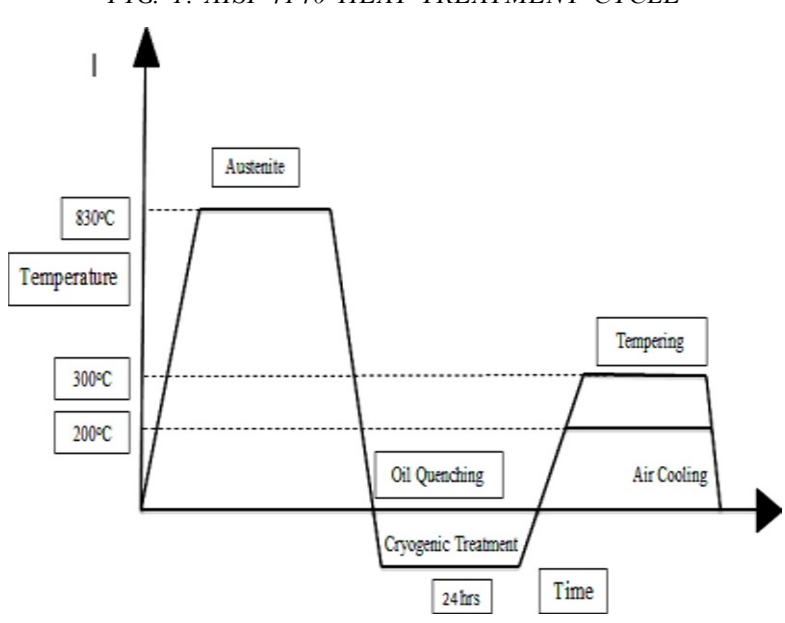

FIG. 2. AISI 4340 HEAT TREATMENT CYCLE

TABLE 1. SPECTROSCOPIC CHEMICAL ANALYSIS OF AISI 4340 STEEL

\begin{tabular}{|c|c|c|c|}
\hline Element & Amount (\%) & Element & Amount (\%) \\
\hline $\mathrm{C}$ & 0.421 & $\mathrm{Ni}$ & 0.482 \\
\hline $\mathrm{Mn}$ & 0.674 & $\mathrm{Mo}$ & 0.020 \\
\hline $\mathrm{Si}$ & 0.288 & $\mathrm{P}$ & 0.023 \\
\hline $\mathrm{Cr}$ & 0.790 & $\mathrm{~S}$ & Balance \\
\hline $\mathrm{Al}$ & 0.029 & $\mathrm{Fe}$ & \\
\hline
\end{tabular}

TABLE 2. SPECTROSCOPIC CHEMICAL ANALYSIS OF AISI 4140 STEEL

\begin{tabular}{|c|c|c|c|}
\hline Element & Amount (\%) & Element & Amount (\%) \\
\hline $\mathrm{C}$ & 0.405 & $\mathrm{Ni}$ & 0.091 \\
\hline $\mathrm{Mn}$ & 0.885 & $\mathrm{Mo}$ & 0.185 \\
\hline $\mathrm{Si}$ & 0.289 & $\mathrm{P}$ & 0.0173 \\
\hline $\mathrm{Cr}$ & 0.962 & $\mathrm{~S}$ & 0.0314 \\
\hline $\mathrm{Al}$ & 0.008 & $\mathrm{Fe}$ & Balance \\
\hline
\end{tabular}

Mehran University Research Journal of Engineering \& Technology, Volume 38, No. 3, July, 2019 [p-ISSN: 0254-7821, e-ISSN: 2413-7219] 
Fig. 3(a) and Table 5 shows hardness as a function of the heat treatment to conventionally heat treated and cryogenic treated specimens. The effect of cryogenic treatment can be seen without being affected by the subsequent tempering process. As it can be seen that by performing conventional heat treatment and the cryogenic treatment there is some increase in hardness. The hardness results for AISI 4140 and AISI 4340 steel are shown in Fig. 3(a) and Table 5. As these hardness values were obtained before tempering, the slight improvement in hardness value is due to the transformation of a large fraction of retained austenite to the BCT (Body Centered Tetragonal) structure of martensite.After tempering, there is small decrease in hardness as shown in Tables 6-7 and Fig. 3(b) respectively. The decrease in hardness after tempering is due to the formation of tempered maternsite and carbides.

TABLE 3. HEAT TREATMENT SEQUENCE FOR AISI 4140 STEEL

\begin{tabular}{|c|c|}
\hline Designation & Heat Treatment \& Cryogenic Treatment \\
\hline Sequence-1 & Austenite at $850^{\circ} \mathrm{C}$, oil Quench \\
\hline Sequence-2 & Austenite at $850^{\circ} \mathrm{C}$, Quenching in oil, temperature at $200^{\circ} \mathrm{C}$ \\
\hline Sequence-3 & Austenite at $850^{\circ} \mathrm{C}$, Quench in oil, temperature at $300^{\circ} \mathrm{C}$ \\
\hline Sequence-4 & Austenite at $850^{\circ} \mathrm{C}$, oil Quench, cryogenic temperature: $-196^{\circ} \mathrm{C}$ \\
\hline Sequence-6 & Austenite at $850^{\circ} \mathrm{C}$, Quenching in oil, cryogenic temperature: $196^{\circ} \mathrm{C}$, temper at $200^{\circ} \mathrm{C}$ \\
\hline Sequence-7 & Austenite at $850^{\circ} \mathrm{C}$, Quenching in oil, cryogenic temperature: $-196^{\circ} \mathrm{C}$, temperature at $300^{\circ} \mathrm{C}$ \\
\hline
\end{tabular}

TABLE 4. HEAT TREATMENT SEQUENCE FOR AISI 4340 STEEL

\begin{tabular}{|c|c|}
\hline Designation & Heat Treatment \& Cryogenic Treatment \\
\hline Sequence-1 & Austenite at $830^{\circ} \mathrm{C}$, Quenching in oil \\
\hline Sequence-2 & Austenite at $830^{\circ} \mathrm{C}$, Quenching in oil, temperature at $200^{\circ} \mathrm{C}$ \\
\hline Sequence-3 & Austenite at $830^{\circ} \mathrm{C}$, Quenching in oil, temperature at $300^{\circ} \mathrm{C}$ \\
\hline Sequence-4 & Austenite at $830^{\circ} \mathrm{C}$, Quenching in oil, cryogenic temperature: $-196^{\circ} \mathrm{C}$ \\
\hline Sequence-6 & Austenite at $830^{\circ} \mathrm{C}$, Quenching in oil, cryogenic temperature: $-196^{\circ} \mathrm{C} 2$, temperature at $00^{\circ} \mathrm{C}$ \\
\hline Sequence-7 & Austenite at $830^{\circ} \mathrm{C}$, oil Quench, cryo temperature:- $196^{\circ} \mathrm{C}$, temperature at $300^{\circ} \mathrm{C}$ \\
\hline
\end{tabular}

TABLE 5. HARDNESS FOR CRYOGENIC AND NON-CRYOGENIC TREATED

\begin{tabular}{|c|c|c|}
\hline Steel Grade & Conventional Oil Quenched (HRC) & Cryogenic Treated (HRC) \\
\hline AISI4340 & 52 & 57 \\
\hline AISI4140 & 51 & 54 \\
\hline
\end{tabular}

TABLE 6. EFFECT OF TEMPERING TEMPERATURES ON HARDNESS OF AISI 4340

\begin{tabular}{|c|c|c|c|}
\hline Specimen No. & Tempering Temperature $\left({ }^{\circ} \mathrm{C}\right)$ & Conventional Oil Quenched (HRC) & Cryogenic Treated (HRC) \\
\hline 1 & 200 & 52 & 54 \\
\hline 2 & 300 & 49.4 & 51 \\
\hline
\end{tabular}

TABLE 7. EFFECT OF TEMPERING TEMPERATURES ON HARDNESS OF AISI 4140

\begin{tabular}{|c|c|c|c|}
\hline Specimen No. & Tempering Temperature $\left({ }^{\circ} \mathrm{C}\right)$ & Conventional Oil Quenched $(\mathrm{HRC})$ & Cryogenic Treated $(\mathrm{HRC})$ \\
\hline 1 & 200 & 50 & 53 \\
\hline 2 & 300 & 49 & 51 \\
\hline
\end{tabular}

Mehran University Research Journal of Engineering \& Technology, Volume 38, No. 3, July, 2019 [p-ISSN: 0254-7821, e-ISSN: 2413-7219] 


\subsection{Impact Testing}

Fig. 4(a) shows the impact toughness of charpy impact test of AISI 4340 and AISI 4140 steel. Similar to the effect of cryogenic treatment on hardness, an attempt was made to isolate the effect of tempering from the cryogenic process. This increase in impact toughness after cryogenic treatment can be attributed to an increase in the amount of tempered martensite that transformed from the retained austenite. In fact, the harder and so finer ductile matrix, leads to the higher impact toughness values obtained. As was already that increase in the amount of tempered martensite is responsible for the higher hardness and impact toughness.

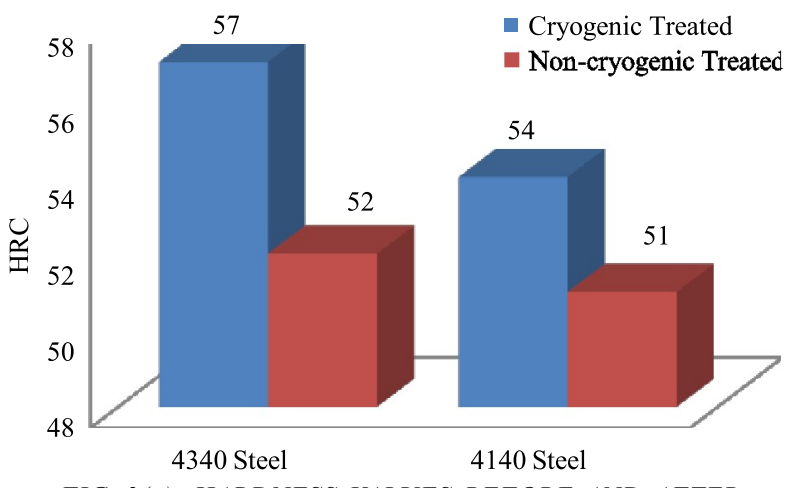

FIG. 3(a). HARDNESS VALUES BEFORE AND AFTER CRYOGENIC TREATMENT

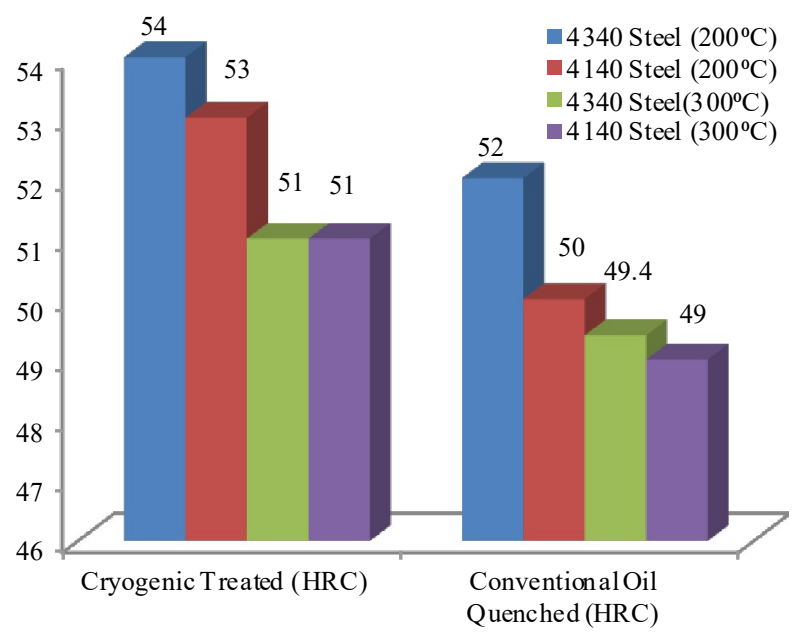

FIG. 3(b). HARDNESS VALUES BEFORE AND AFTER CRYOGENIC TREATMENT WITH TEMPERING TEMPERATURES
For AISI 4340, the impact toughness after cryogenic treatment and then tempering at 200 and $300^{\circ} \mathrm{C}$ become increases as 14.3 and $16.6 \mathrm{~J}$ respectively, which is greater than conventional quench and tempered sample for the same tempering temperatures as shown in Tables 8-9 and Fig. 4(b). The impact strength for AISI 4140 after cryogenic treatment and then tempering at 200 and $300^{\circ} \mathrm{C}$ become increases as 17.5 and $27 \mathrm{~J}$ respectively, which is greater than conventional quench and tempered sample for the same tempering temperatures as shown in Table 10.

\subsection{Tensile Testing}

Both conventional and cryogenic treated samples were tested for tensile testing according ASTM standard

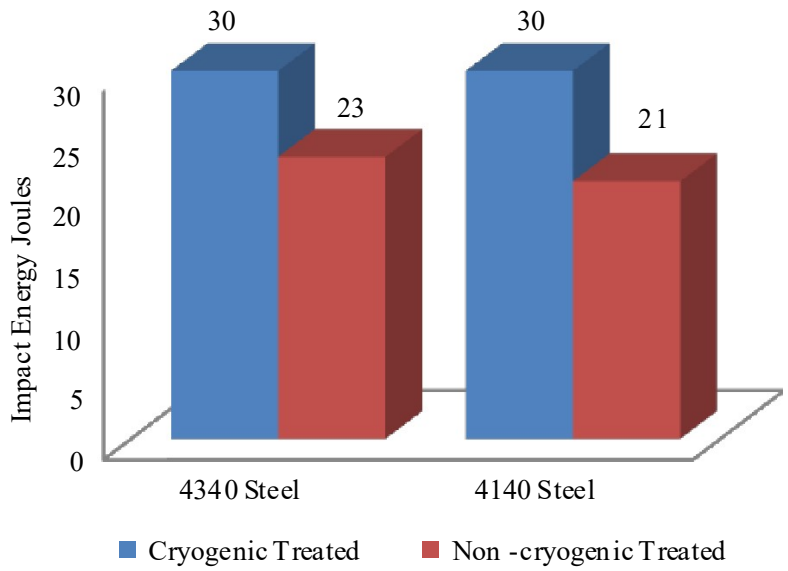

FIG. 4(a). IMPACT ENERGY VALUES BEFORE AND AFTER CRYOGENIC TREATMENT

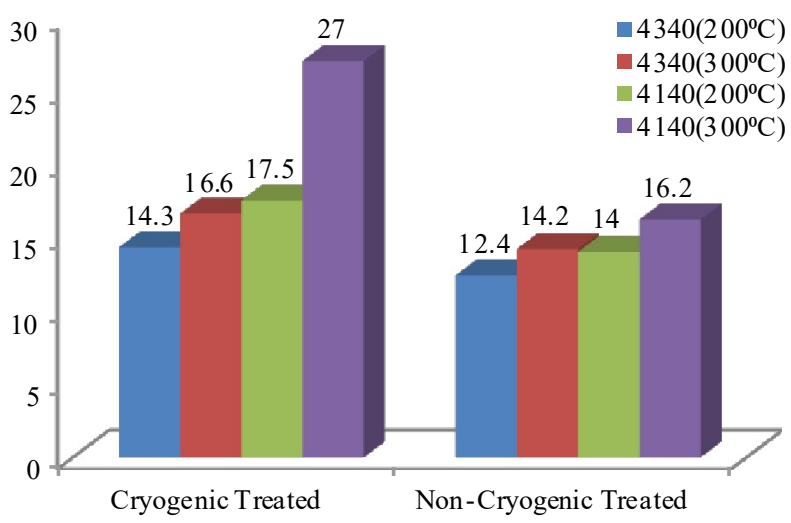

FIG. 4(b). IMPACT ENERGY (J) VALUES BEFORE AND AFTER CRYOGENIC TREATMENT WITH TEMPERING TEMPERATURES

Mehran University Research Journal of Engineering \& Technology, Volume 38, No. 3, July, 2019 [p-ISSN: 0254-7821, e-ISSN: 2413-7219] 
ASTM-E8. Fig. 5(a-b)and Table 11 show the experimental results of tensile strength for oil quenched and cryogenic treated samples respectively. From Fig. 5(a-b) and Table 11 , it is clear that there is an increase in tensile strength after cryogenic treatment of AISI 4340 and AISI 4140. The increase in amount of martensite after cryogenic treatment gives rise to the tensile strength of medium carbon steel alloys as shown in Table 11.

\subsection{Optical Microscopy}

The microstructures of AISI 4340 and AISI 4140 have been analyzed in Optical Microscope with 2\% nitalas a etchant at magnification 200x. From the Fig. 6(a), the microstructure shows the formation of martensite laths and white region of retained austenite in AISI 4340. An increase in fraction of martensite is due to decrease in fraction of retained austenite at cryogenic temperature shown in Fig. 6(b). The white region in Fig. 6(a-b) shows the presence of retained austenite with martensite needles like structure. The higher amount of white region i.e. retained austenite has been observed in conventional quenching whereas the cryogenic treated samples has small amount of retained austenite. The reduction in the amount of retained austenite in cryogenic treated samples is attributed to the drastic cooling from room temperature to $-196^{\circ} \mathrm{C}$ for 24 hours, thus large fraction of martensite formed with fine lath

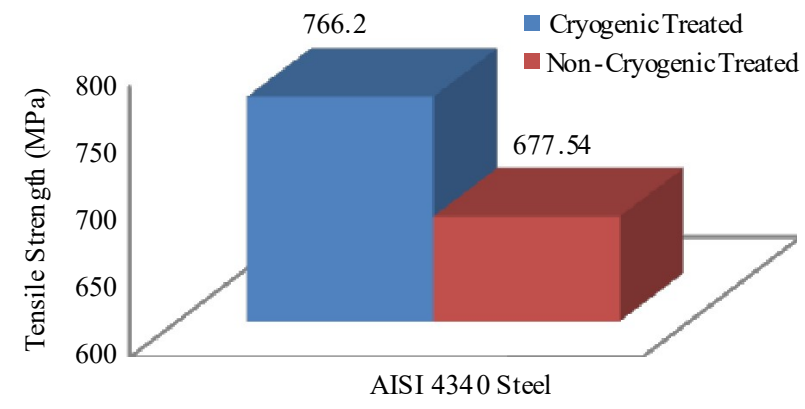

FIG. 5(a). TENSILE STRENGTH VALUES BEFORE AND AFTER CRYOGENIC. TREATMENT FOR AISI 4340 STEEL

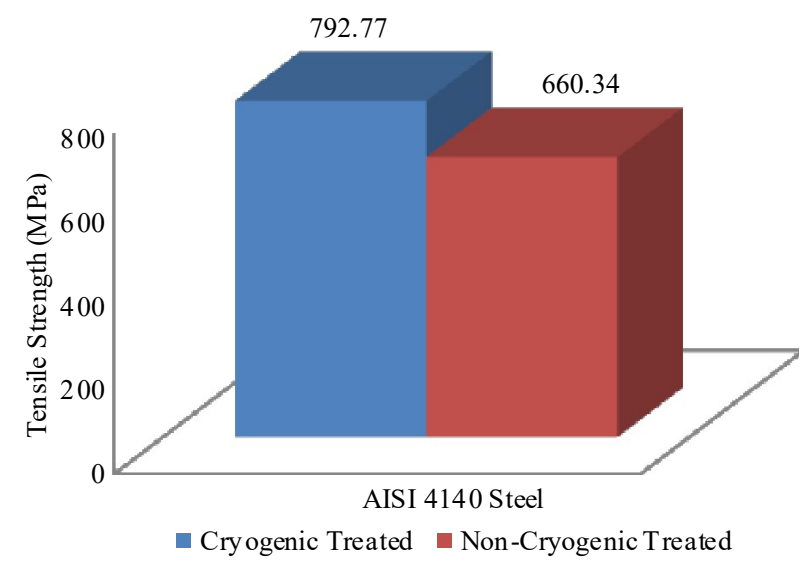

FIG. 5(b). TENSILE STRENGTH VALUES BEFORE AND AFTER CRYOGENIC TREATMENT FOR AISI 4140 STEEL.

TABLE 8. IMPACT TOUGHNESS (J) FOR CRYOGENIC AND NON-CRYOGENIC TREATED

\begin{tabular}{|c|c|c|}
\hline Steel Grade & Conventional Oil Quenched (J) & Cryogenic Treated (J) \\
\hline AISI4340 & 23 & 30 \\
\hline AISI4140 & 21 & 30 \\
\hline
\end{tabular}

TABLE 9. IMPACT TOUGHNESS VALUES AT DIFFERENT TEMPERING TEMPERATURES FOR AISI 4340 STEEL

\begin{tabular}{|c|c|c|c|}
\hline Specimen No. & Tempering Temperature $\left({ }^{\circ} \mathrm{C}\right)$ & Conventional Oil Quenched $(\mathrm{J})$ & Cryogenic Treated $(\mathrm{J})$ \\
\hline 1 & 200 & 12.4 & 14.3 \\
\hline 2 & 300 & 14.2 & 16.6 \\
\hline
\end{tabular}

TABLE 10. IMPACT TOUGHNESS VALUES AT DIFFERENT TEMPERING TEMPERATURES FOR AISI 4140 STEEL

\begin{tabular}{|c|c|c|c|}
\hline Specimen No, & Tempering Temperature $\left({ }^{\circ} \mathrm{C}\right)$ & Conventional Oil Quenched $(\mathrm{J})$ & Cryogenic Treated $(\mathrm{J})$ \\
\hline 1 & 200 & 14 & 17.5 \\
\hline 2 & 300 & 16.2 & 27 \\
\hline
\end{tabular}

Mehran University Research Journal of Engineering \& Technology, Volume 38, No. 3, July, 2019 [p-ISSN: 0254-7821, e-ISSN: 2413-7219] 
structure. From Fig. 6(c-f), the microstructure indicates the martensite presence with very little amount of retained austenite and precipitated carbide particles. The tempering at $200^{\circ} \mathrm{C}$ after conventional quenching gives uneven carbides distribution as compare to the evenly distributed carbides after cryogenic treatment as shown in Fig. 6(c-d) whereas tempering at $300^{\circ} \mathrm{C}$ after conventional quenching the carbides size become coarsen with uneven distribution as in Fig. 6(e) as compared to the evenly distributed carbide in Fig. 6(f). The Fig. $6(\mathrm{~d}-\mathrm{f})$ at $200^{\circ} \mathrm{C}$ temper and $300^{\circ} \mathrm{C}$ temper respectively show the difference in the carbides sizes due to different tempering temperatures. Because of the formation of tempered martensite and large amount of evenly distributed carbides the tensile strength and toughness increases for cryogenic treated samples. Similar mechanism has been observed for AISI 4140 and shown in Fig. 6(g-1).

\subsection{Scanning Electron Microscopy}

The surface of AISI 4340 and AISI 4140 steel samples were analyzed for both conventional and cryogenic treatments using scanning electron microscopy. The Fig. 7(a-b) shows the SEM images for AISI 4340 steel after conventional and cryogenic treatment respectively, whereas the Fig. 7(d-e) shows the SEM images for AISI 4140 after conventional quenching andcryogenic treatment respectively. The SEM images show that the carbides distribution in cryogenic treated specimen improved drastically as compare to conventional quenching. After cryogenic treatment, the carbides become more evenly distributed. Fig. 7(c-e) shows the presence of martensitic laths with carbides precipitations due to formation of tempered martensite. The formation of tempered martensite increases the impact strength of both steel grades. Carbides formation and the transformation of retained austenite to more evenly distributed martensite increase the hardness and tensile strength of cryogenic treated samples.

\subsection{Fractography}

There are many types of fracture happen by a process involving crack initiation, crack propagation and breaking (fracture). The fracture surface of AISI 4340 steel was examined after tensile testing using SEM to determine the fracture mode as shown in Fig. 8. It has been observed from Fig. 8(a-b), the fracture surface of conventionally treated AISI 4340 steel, crack was initiated at the center of the specimen possibly due to embrittlement of martensitic structure start to propagate and finally fracture occur.

The fracture surfaces of the cryogenic treatment specimens have been compared with those conventionally treated. Fig. 8(c-d) shows the cryogenic treatment increases the nucleation of carbides, and facilitates the precipitation of large number density of carbides thereby increases the impact toughness

TABLE 11. TENSILE STRENGTH VARIATION BEFORE AND AFTER CRYOGENIC TREATMENT

\begin{tabular}{|c|c|c|}
\hline Steel Grade & Conventional Oil Quenched (MPa) & Cryogenic Treated (MPa) \\
\hline AISI 4340 & 677.54 & 766.20 \\
\hline AISI 4140 & 660.34 & 792.77 \\
\hline
\end{tabular}

Mehran University Research Journal of Engineering \& Technology, Volume 38, No. 3, July, 2019 [p-ISSN: 0254-7821, e-ISSN: 2413-7219] 


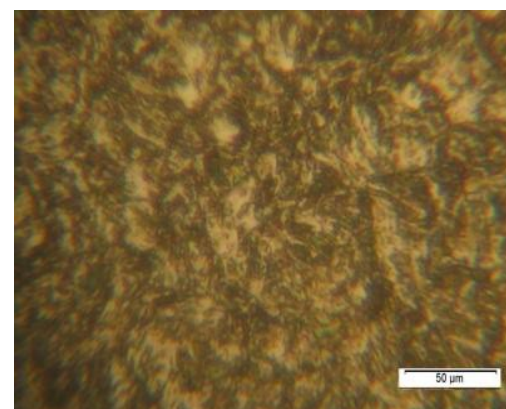

(a) CONVENTIONAL QUENCHED AT $830^{\circ} \mathrm{C}$

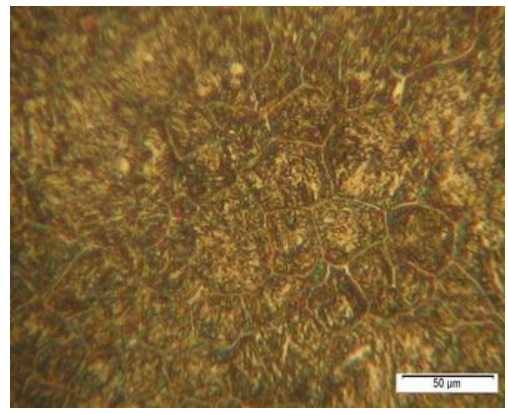

(d) TEMPERED AT $200^{\circ} \mathrm{C}$ AFTER CRYOGENIC TREATMENT

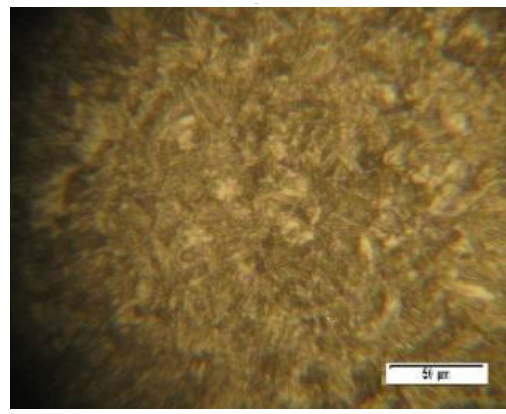

(b) CRYOGENIC TREATED

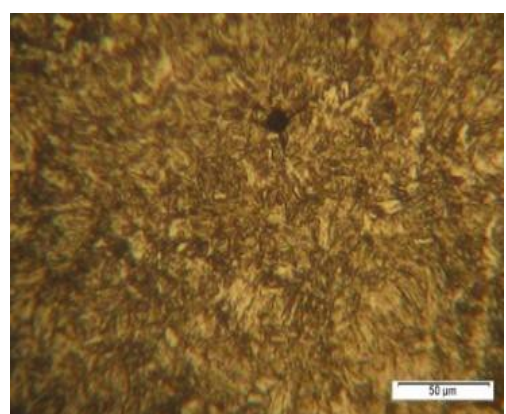

(e) TEMPERED AT $300^{\circ} \mathrm{C}$ AFTER CONVENTIONAL QUENCHING

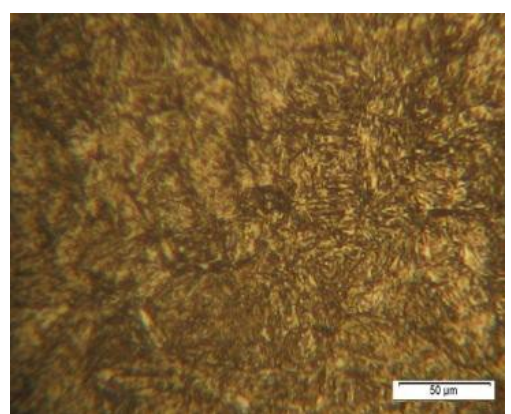

(c) TEMPERED AT $200^{\circ} \mathrm{C}$ AFTER CONVENTIONAL QUENCHING

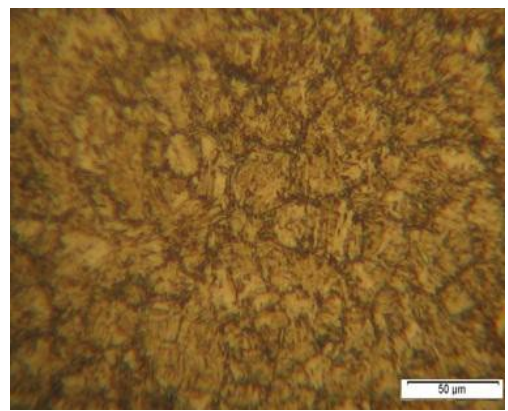

(f) TEMPERED AT $300^{\circ} \mathrm{C}$ AFTER CRYOGENIC TREATMENT

FIG. 3.4. OPTICAL MICROGRAPHS OF AISI 4340 STEEL, ETCHANT USED AS 2\% NITAL; MAGNIFICATION $200 X$

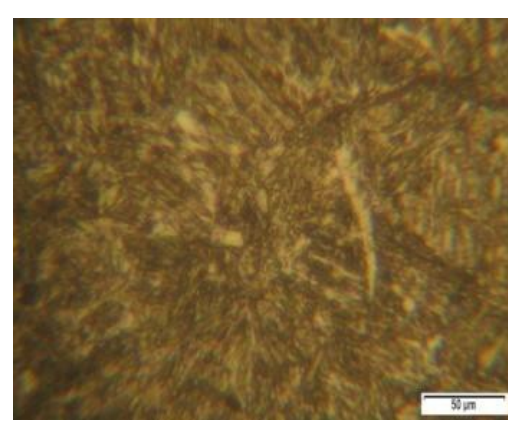

(g) CONVENTIONAL QUENCHED AT $850^{\circ} \mathrm{C}$

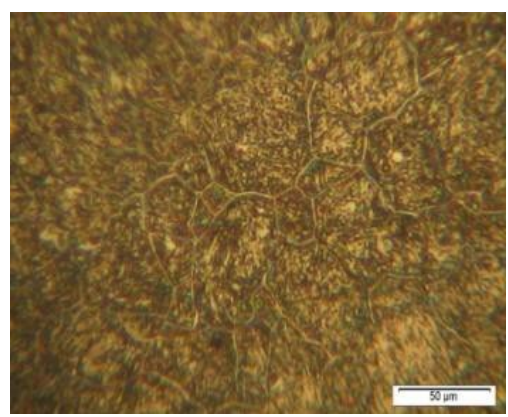

(j) TEMPERED AT $200^{\circ} \mathrm{C}$ AFTER CRYOGENIC TREATMENT

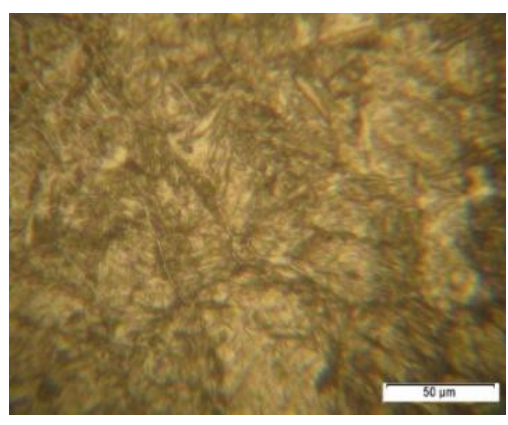

(h) CRYOGENIC TREATED

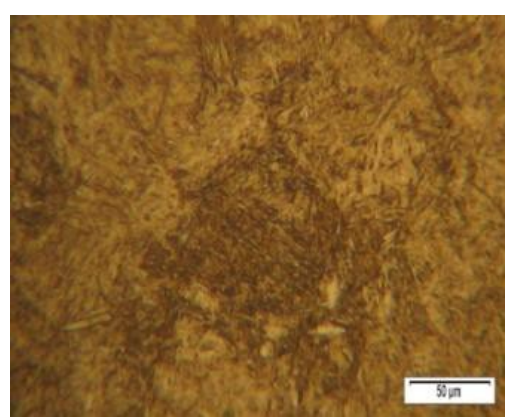

(k) TEMPERED AT $300^{\circ} \mathrm{C}$ AFTER CONVENTIONAL QUENCHING

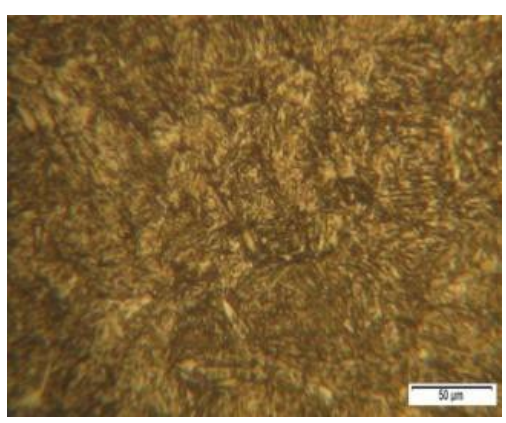

(i) TEMPERED AT $200^{\circ} \mathrm{C}$ AFTER CONVENTIONAL QUENCHING

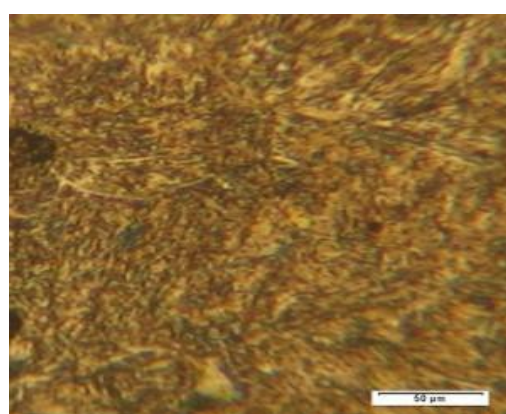

(l) TEMPERED AT $300^{\circ} \mathrm{C}$ AFTER CRYOGENIC TREATMENT.

FIG. 6. OPTICAL MICROGRAPHS OF AISI 4140 STEEL, ETCHED IN 2\% NITAL; MAGNIFICATION $200 X$ 
values. During cryogenic heat treatment fine platelets of martensite are formed from the retained austenite and it promote the precipitation of fine carbides by a diffusion mechanism during tempering. The center of the fracture surface of the cryogenic treated specimen shows a failure initiated from the center of the crosssection by micro void coalescence and propagated radially outward.

The fracture surface of AISI 4140 steel was analyzed after tensile testing using SEM to determine the mode of fracture. Three regions can be distinguished in AISI 4340 steel at the conventionally treated stage. The crack initiation process for the specimens tested in the residue paste is linked with the development of corrosion pits on the sample surface. Fig. 8(e) shows an area near the fracture surface of a sample tested. Cracks can be seen emitting from the pits. Coalescence of these all cracks normal to the tensile axis has been observed. A magnified view of the center of the specimen as shown in Fig. 8(h) dimple rupture and tearing shows ductile failure mode in medium carbon low alloy steel.

\section{CONCLUSIONS}

This experimental work was conducted to analyze the effect of cryogenic treatment on mechanical properties of AISI 4140 and AISI 4340. The results of cryogenic treated samples were compared with oil quenched samples.

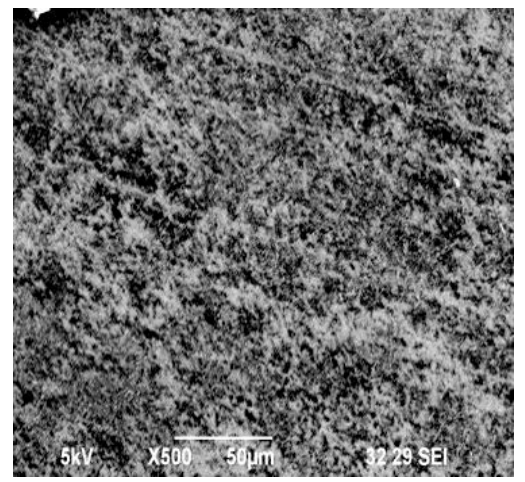

FIG. 7(a). CONVENTIONAL QUENCHED AISI 4340 STEEL

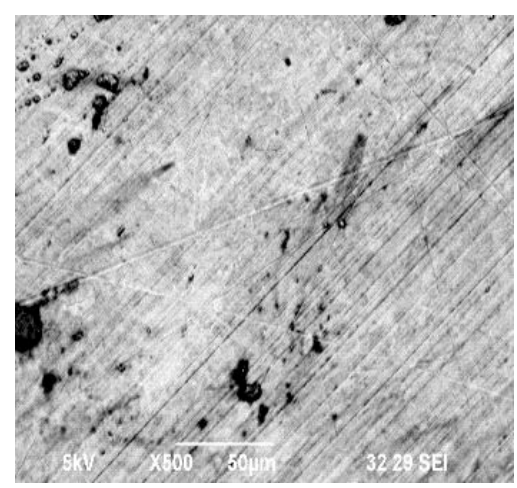

FIG. 7(d). CONVENTIONAL QUENCHED AISI 4140 STEEL

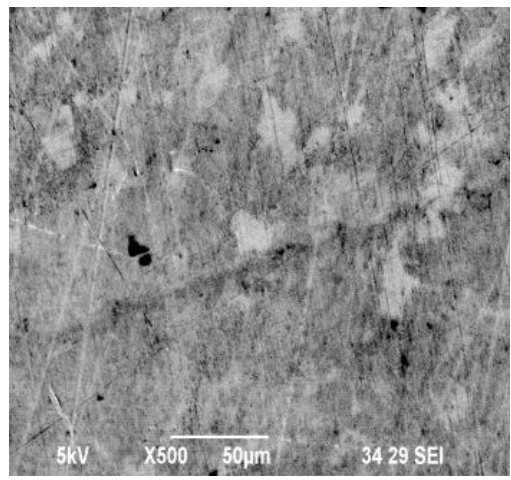

FIG. 7(b). CRYOGENIC TREATED AISI 4340 STEEL

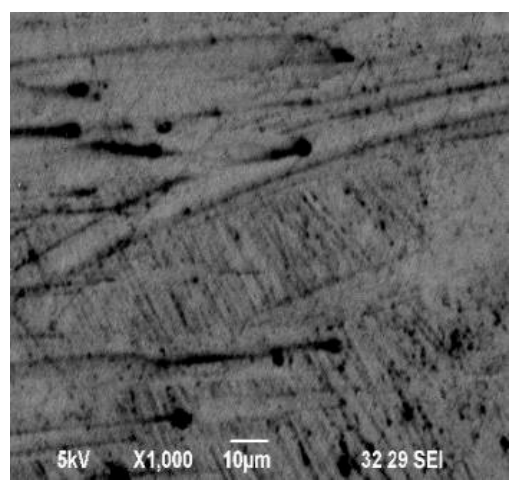

FIG. 7(e). CRYOGENIC TREATED AISI 4140 STEEL

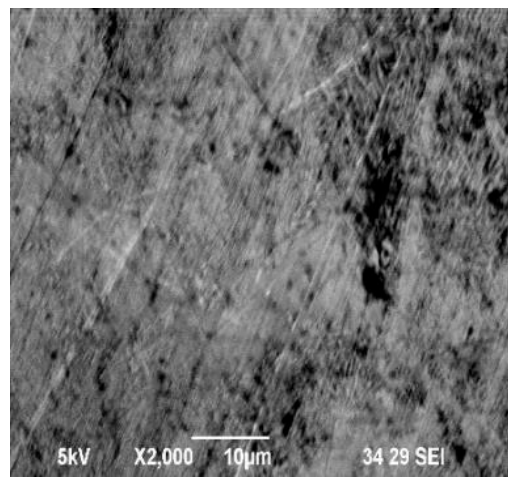

FIG. 7(c). TEMPERED AT $300^{\circ} \mathrm{C}$ AISI 4340 STEEL

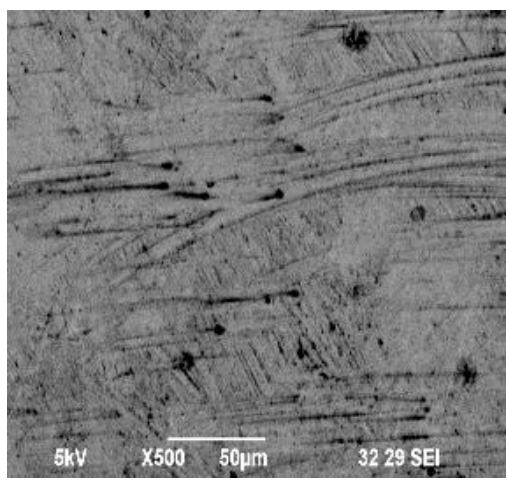

FIG. 7(f). TEMPERED AISI 4140 STEEL AT $300^{\circ} \mathrm{C}$ AFTER CRYOGENIC TREATMENT

Mehran University Research Journal of Engineering \& Technology, Volume 38, No. 3, July, 2019 [p-ISSN: 0254-7821, e-ISSN: 2413-7219] 
It is clear from experimental results that the cryogenic treatment should be followed by tempering treatment to enhance the impact toughness. Since tempering treatment allows the formation of precipitation of carbide

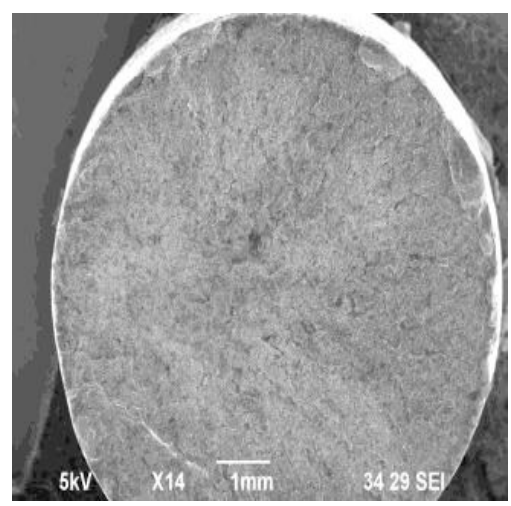

(a) FRACTURE SURFACE AFTER TENSILE TESTING

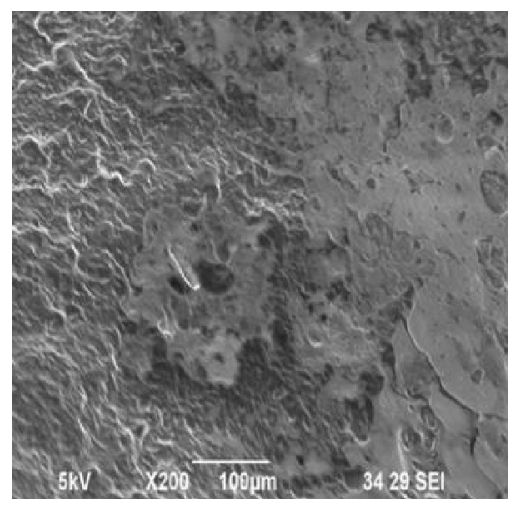

(d) THE DIMPLE RUPTURE AND TEARING AT CENTRE

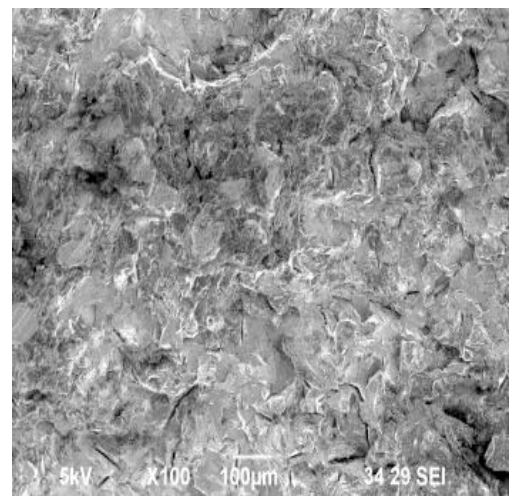

(b)CRACK REGION

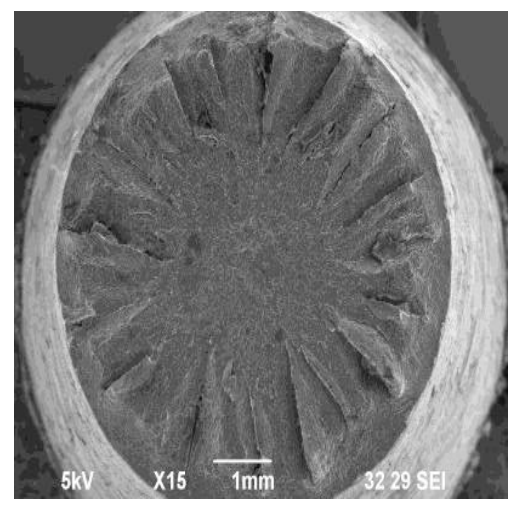

(e) THIS FIGURE SHOWING CUP AND CONE FRACTURE OF AN AISI 4140 STEEL SPECIMEN

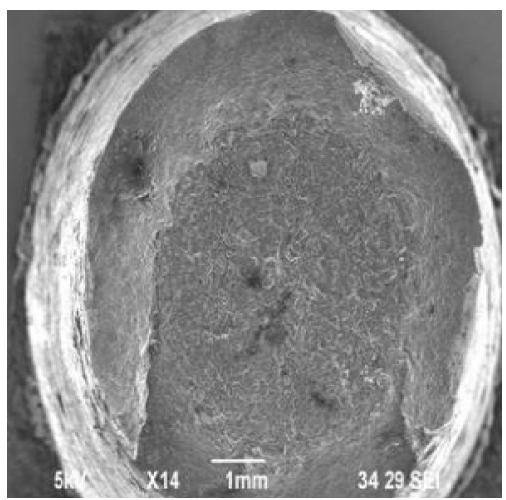

(c) A CUP-CONE FRACTURE OF A SPECIMEN

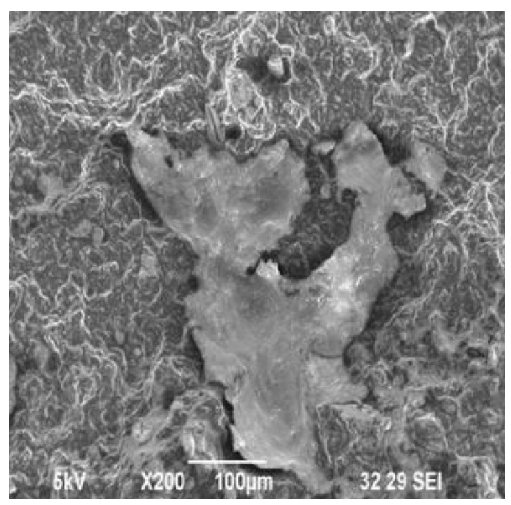

(f) HIGH-MAGNIFICATION VIEW OF DUCTILE DIMPLE FRACTURE. CRACK GROWTH DIRECTION IS FROM BOTTOM TO TOP

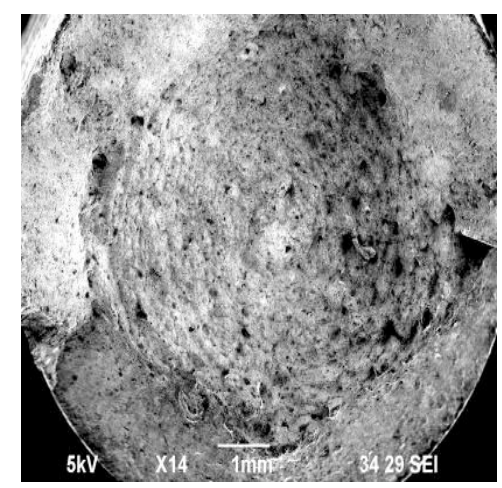

(g) AISI 4140 STEEL CONE FRACTURE SURFACE APPEARANCE

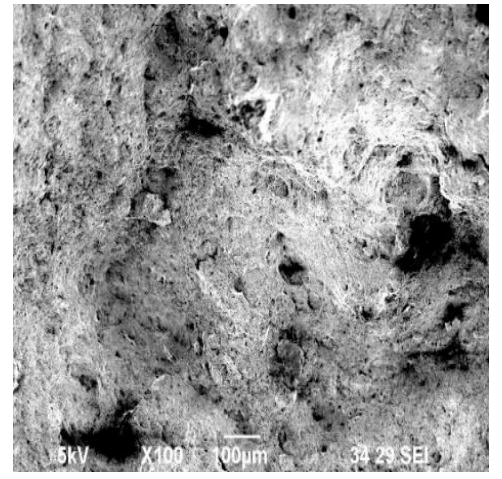

(h) SECONDARY CRACKS FOLLOW COMBINED TRANSGRANULAR AND INTERGRANULAR PATHS IN THIS REGION

FIG. 8. SEM MICROGRAPHS OF AISI 4140 STEEL SHOWING FRACTURE SURFACES 
leads to increase impact toughness. The results show that after cryogenic treatment and tempering, retained austenite transformation to martensite and presence of carbides precipitations are responsible for mechanical strength (i.e. hardness, tensile strength and impact toughness) of AISI 4340 and AISI 4140. The tempering treatment on the samples at different temperatures showed that lower tempering temperature will increase the hardness and decrease the impact toughness and vice versa.

\section{ACKNOWLEDGEMENT}

The authors would like to recognize and appreciate the efforts and inputs of faculty members of the Metallurgy and Materials Engineering Department, Mehran University of Engineering \& Technology in conducting the $2^{\text {nd }}$ National Conference on Metallurgy and Materials Engineering and providing a platform for researchers in presenting their research papers and also the authors wish to thank Dawood University of Engineering \& Technology and NED University of Engineering \& Technology for providing access to all lab facilities.

\section{REFERENCES}

[1] Wilkins, C., "Cryogenic Processing: The Big Chill", EDM Today, pp. 36 44, 1999.

[2] Baldissera, P., and Delprete, C., "Deep Cryogenic Treatment: A Bibliographic Review”, Open Mechanical Engineering Journal, Volume 2, pp. 1, 2008.

[3] Koneshlou, M., Asl, H.M., and Khomamizadeh, F., "Effect of Cryogenic Treatment on Microstructure, Mechanical and Wear Behaviors of AISI H13 Hot Work Tool Steel", Cryogenics, Volume 51, pp. 55, 2011.
[4] Firouzdor, V., Nejati, E., and Khomamizadeh, F., "Effect of Deep Cryogenic Treatment on Wear Resistance and Tool Life of M2 HSS Drill”, Journal of Materials Processing Technology, Volume 206, pp. 467, 2008.

[5] Lal, D.M., Renganarayanan, S., and Kalaindhi, A., "Cryoenic Treatment to Augment Wear Resistance of Tool and Die Steel", Cryogenics, Volume 41, pp. 149, 2001.

[6] Popandopulo, N., and Zhukova, L.T., "Transformation in High Speed Steels During Cold Treatment", Metallurgical Science Heat Treatment, Volume 22, pp. 708-710, 1980.

[7] Albert, M., "Cutting Tools in the Deep Freeze", Modem Machine Shop, pp. 54-61, 1992.

[8] Mahmudi, R., and Faraji, H.R., "Effect of Cryogenic Treatments on the Mechanical Properties and Wear Behavior of High-Speed Steel M2", Heat Treatment Metallurgy, Volume 27 pp. 69-72, 2000.

[9] Meng, F., Tagashira, K., Azuma, R., and Sohma, H., "Role of Eta-Carbide Precipitation in the Wear Resistance Improvements of Fe-12Cr-Mo-V-1.4C Tool Steel by Cryogenic Treatment", ISIJ International, Volume 34, pp. 205-210, 1994.

[10] Kelker, R., and Nash, P, "The Mechanism of Property Enhancement in M2 Tool Steel by Cryogenic Treatment", Thermal Processing Technology Centre, Volume, 11, pp. 13-19, 2003.

[11] Zablotskii, V.K., Pisklich, M.M., Vojakin, V.N., and Sharaban, N.D., "Examination of Transformations during Tempering of High-Speed Steels", Material \& Metal International, Volume 50, pp. 345-351, 1988.

[12] Reitz, W., and Pendray, J., "Cryoprocessing of Materials: A Review of Current Status", Materials and Manufacturing Processes, Volume 16, No. 6, pp.829-840, 2006.

[13] Collins, D.N., and Dormer, "Deep Cryogenic Treatment of a D2 Cold-Work Tool Steels", Heat Treatment of Metals, Volume 3, pp.71-74, 1997. 
[14] Molinari, A., Pellizzari, M., Gialanella, S., Straffelini, G., and Stiasny, K.H., "Effect of Deep Cryogenic Treatment on the Mechanical Properties of Tool Steels", Journal of Materials Process Technology, Volume 8, pp. 350-355, 2001.

[15] Nirmal, S., Sehgal, R., and Sharma, V., "Cryogenic Treatment of Tool Materials: A Review", Materials and Manufacturing Processes, Volume 25, pp. 1077-1100, 2010 .
[16] Barron, R.F., "Cryogenic Treatment of Metals to Improve Wear Resistance”, Cryogenics, Volume 22, pp. 409-414, 1982 .

[17] Dong, Y., Lin, X.P., and Xiao, H.S., "Deep Cryogenic Treatment of High-Speed Steel and Its Mechanism," Heating Treatment of Metal, Volume 25, pp. 55-59, 1998. 